\title{
Genetic factors and osteoporotic fractures in elderly people: prospective 25 year follow up of a nationwide cohort of elderly Finnish twins
}

\author{
Pekka Kannus, Mika Palvanen, Jaakko Kaprio, Jari Parkkari, Markku Koskenvuo
}

\begin{abstract}
Accident and
Trauma Research

Center and the

Tampere Research

Center of Sports

Medicine, UKK

Institute for Health

Promotion

Research, PO Box

30, FIN-33501

Tampere, Finland

Pekka Kannus

chief physician

Mika Palvanen

research fellow

Jari Parkkari

research fellow

Department of

Public Health,

University of

Helsinki, PO Box

41, FIN-00014,

Helsinki, Finland

Jaakko Kaprio

professor

Department of

Public Health,

University of Turku,

FIN 20520, Turku,

Finland

Markku Koskenvuo

professor

Correspondence to:

P Kannus UKK

Institute,

Kaupinpuistonkatu

1, FIN-33500

Tampere, Finland

klpeka@uta.fi
\end{abstract}

BMJ 1999;319:1334-7

website

extra

Further results can

be found on the

BMJ's website

www.bmj.com

\begin{abstract}
Objective To determine whether genetic factors partly explain variation in risk of osteoporotic fracture, the true end point of the osteoporosis problem.
\end{abstract}

Design Prospective 25 year follow up of a nationwide cohort of elderly Finnish twins.

Setting The Finnish twin cohort and the national hospital discharge register, covering the entire 5 million population of Finland.

Subjects All same sex twin pairs born before 1946 . The cohort contained 2308 monozygotic and 5241 dizygotic twin pairs (15 098 people) at the beginning of follow up.

Main outcome measure The number and concordance of osteoporotic fractures in the twin pairs, 1972-96.

Results 786 cohort members sustained an osteoporotic fracture. In women, the pairwise concordance rate for fracture (that is, the relative number of twin pairs in whom the fracture affected both twins in a pair) was $9.5 \%$ (95\% confidence interval $5.3 \%$ to $15.5 \%$ ) in monozygotic pairs and $7.9 \%(5.2 \%$ to $11.4 \%)$ in dizygotic pairs. In men, the figures were $9.9 \%$ (4.4\% to $18.5 \%$ ) and $2.3 \%$ (0.6\% to $5.7 \%)$

Conclusions Susceptibility to osteoporotic fractures in elderly Finns is not strongly influenced by genetic factors, especially in elderly women. The traditional strategy for prevention of osteoporotic fractures - that is, increasing peak bone mass and preventing age related bone loss-should be changed to include new elements such as prevention of falls and protection of the critical anatomical sites of the body when a fall occurs.

\section{Introduction}

The large number of osteoporotic fractures among elderly people represents a worldwide epidemic, and the predicted ageing of populations will further increase the burden of these minimal trauma fractures on our healthcare systems. ${ }^{1-4}$ In addition to high costs, osteoporotic fractures are associated with high morbidity and disability, high risk for long term institutionalisation, and increased risk of death. ${ }^{1-5}$

Bone mineral density and bone mineral content, as measured by absorptiometry, are predictors of osteoporotic fractures of the spine and proximal femur, the sites of clinically important fractures. ${ }^{167}$ Twin and other types of family studies have, in turn, consistently shown that genetic determinants have a substantial role in explaining age specific variation between individual people in bone mineral density and bone mineral content at various anatomical sites of a skeleton, ${ }^{8-13}$ heritability thus being an important deter- minant of risk for osteoporosis in elderly women. ${ }^{13}$ Nevertheless, despite the fact that reduction of the number of fractures can be the only ultimate goal in the prevention and treatment of osteoporosis, previous twin studies have not directly examined whether genetic factors can explain some of the variation in risk of osteoporotic fracture in elderly people.

We examined whether genetic factors in elderly individual people are related to their susceptibility to osteoporotic fracture. We thought that this information would be valuable and of help in planning the strategies for fracture prevention. Our hypothesis or suspicion was that the role of genetic factors is not so clear cut when the end point of the study is changed from osteoporosis to actual fractures.

\section{Methods}

\section{The Finnish twin cohort}

The Finnish twin cohort comprises all same sex twin pairs born before 1958 with both cotwins alive in 1975 . An extensive questionnaire was posted to the twins in 1975 to confirm twinship, determine zygosity, and obtain data on health related variables. The overall response rate was $89 \%$.

Twin zygosity was determined by examining the responses of both members of each twin pair to two questions on the similarity of appearance at school age, items similar to those used in other large twin samples. ${ }^{14-16}$ A set of decision rules was then used to classify the twin pairs as monozygotic, dizygotic, or undetermined zygosity. The validity of the zygosity was studied in a subsample of 104 pairs, and the agreement in classification from the questionnaires and 11 blood markers was $100 \%{ }^{17}$ The estimated probability of misclassification was $1.7 \%$.

The total number of twin pairs born before 1946 was 7549 at the beginning of the prospective follow up of the cohort. Of these, 2308 were monozygotic pairs and 5241 dizygotic pairs. Among the monozygotic pairs, 1221 pairs were female and 1087 male, while among the dizygotic pairs, 2618 pairs were female and 2623 male. The approximately 2:1 dizygotic to monzygotic ratio reflects the high rate of twinning in Finland during the first half of the 20th century, a phenomenon discussed in detail elsewhere. ${ }^{18}$

\section{Identification of osteoporotic fractures among} twins

Using the guidelines from previous epidemiological studies of osteoporotic fractures ${ }^{2} 1920$ we defined an osteoporotic fracture as a fracture that occurred in a person aged 50 years or more as a consequence of a only minimal trauma-that is, a fall from standing height or less. Fractures caused by a vehicular accident or other high energy trauma could be excluded as the Finnish national hospital discharge register also 
contains data on cause of injury. Previous investigations indicated that most osteoporotic fractures occur at hip, pelvis, knee (distal femur, patella, or proximal tibia), ankle, thoracic and lumbar spine, ribs, proximal and distal humerus, and wrist, and therefore these anatomical sites were used in this study too.

According to the above described age criterion, all 50 year old or older twin cohort members who were admitted to Finnish hospitals (1972-96) for primary treatment of an osteoporotic fracture were selected from the national hospital discharge register. Our register is the oldest nationwide discharge register in the world and its accuracy and coverage have been shown to be good (in injuries, 95\% and over) and these percentages are particularly good in severe injuries such as bone fractures. ${ }^{21-23}$

\section{Determination of concordance and risk of fracture among twins}

Twin similarity for osteoporotic fractures was summarised by estimates of concordance. This could be assessed from two types of concordance (termed pairwise and probandwise), each calculated separately for monozygotic and dizygotic pairs. ${ }^{24}$ The $95 \%$ confidence intervals for concordance of fractures were also computed.

The pairwise concordance is the relative number of twin pairs in whom disease (osteoporotic fracture) has affected both twins in a pair, and it is calculated with a formula of $\mathrm{C} / \mathrm{C}+\mathrm{D}$, in which $\mathrm{C}$ is the number of concordant pairs and $\mathrm{D}$ is the number of discordant pairs. ${ }^{25}$ The probandwise concordance is defined as an individual's risk of disease (the conditional probability that one twin is affected, given that his or her cotwin is affected) and as such can be compared with the probability of disease for an individual in the general population. The probandwise concordance is calculated with a formula of $2 \mathrm{C} /(2 \mathrm{C}+\mathrm{D}){ }^{25}$

The overall cumulative risk for fracture (with 95\% confidence intervals) was calculated by dividing the number of fracture cases by the total number of individuals. The relative fracture risk (with 95\% confidence intervals) was, in turn, calculated by dividing the above noted probandwise concordance by this overall cumulative fracture risk.

\section{Results}

Overall cumulative risk for fracture-Between 1972 and 1996, 786 cohort members sustained an osteoporotic fracture that required hospital treatment, the overall cumulative risk for fracture being similar in monozygotic twins (all 5.4\%; men 41\%; women 6.6\%) and dizygotic twins (all 5.1\%; men 3.5\%; women 6.8\%) (table).

Pairwise concordance for fracture-The pairwise concordance for fracture was 9.6\% (95\% confidence interval $6.2 \%$ to $14.2 \%$ ) in monozygotic pairs and $5.9 \%$ $(4.0 \%$ to $8.4 \%)$ in dizygotic pairs, the observed difference of $3.7 \%$ having a confidence interval of $-0.6 \%$ to $8.1 \%$. By sex, this concordance was $9.9 \%$ in monozygotic male pairs (9.5\% in women) and $2.3 \%$ in dizygotic male pairs (7.9\% in women) (table). In hip fractures, the pairwise concordance was $7.8 \%$ (3.4\% to $15.0 \%)$ in monozygotic pairs and $6.7 \%(3.5 \%$ to $12.0 \%)$ in dizygotic pairs, the difference of $1.0 \%$ having a confidence interval of $-5.3 \%$ to $7.4 \%$.

Probandwise concordance for fracture-The probandwise concordance for fracture was $17.6 \%(11.2 \%$ to $24.0 \%)$ in monozygotic pairs and $11.2 \%$ (7.5\% to $14.9 \%$ ) in dizygotic pairs. By sex, this concordance was $18.0 \%$ in male monozygotic pairs ( $17.4 \%$ in women) and $4.4 \%$ in male dizygotic pairs (14.6\% in women) (table). In hip fractures the probandwise concordance was $14.4 \%(5.5 \%$ to $23.0 \%)$ in monozygotic pairs and $12.6 \%(6.2 \%$ to $19.0 \%)$ in dizygotic pairs.

Relative risk for fracture - In men the relative risk for fracture was 4.39 (2.70 to 7.16) in monozygotic pairs and 1.28 (0.64 to 2.56) in dizygotic pairs (table) Among women, the risks were 2.64 (1.83 to 3.81) and 2.16 (1.65 to 2.83), respectively. In hip fractures, the relative fracture risk was 5.99 (3.68 to 9.78) in monozygotic pairs and 6.97 (4.67 to 10.4 ) in dizygotic pairs.

Site specific results-The numbers of specific fractures except hip fracture were not large enough for

Pairwise distribution of twins with osteoporotic fracture in Finnish twin cohort*

\begin{tabular}{|c|c|c|c|c|c|c|c|c|}
\hline Detail & $\begin{array}{l}\text { Total No of } \\
\text { pairs }\end{array}$ & $\begin{array}{c}\text { Fracture } \\
\text { cases }\end{array}$ & $\begin{array}{c}\text { Overall cumulative } \\
\text { fracture risk† }(95 \% \mathrm{CI})\end{array}$ & $\begin{array}{l}\text { Discordant } \\
\text { pairs (D) }\end{array}$ & $\begin{array}{l}\text { Concordant } \\
\text { pairs (C) }\end{array}$ & $\begin{array}{l}\text { Pairwise concordance } \neq \\
(95 \% \mathrm{Cl})\end{array}$ & $\begin{array}{c}\text { Probandwise } \\
\text { concordance§ }(95 \% \mathrm{CI})\end{array}$ & $\begin{array}{l}\text { Relative fracture riskT } \\
(95 \% \mathrm{CI})\end{array}$ \\
\hline \multicolumn{9}{|l|}{ All pairs } \\
\hline Male MZ & 1087 & 89 & $0.041(0.033$ to 0.050$)$ & 73 & 8 & $0.099(0.044$ to 0.185$)$ & $0.180(0.072$ to 0.29$)$ & 4.39 (2.70 to 7.16$)$ \\
\hline Female MZ & 1221 & 161 & $0.066(0.057$ to 0.077$)$ & 133 & 14 & $0.095(0.053$ to 0.155$)$ & $0.174(0.095$ to 0.25$)$ & 2.64 (1.83 to 3.81$)$ \\
\hline Female DZ & 2618 & 355 & $0.068(0.061$ to 0.075$)$ & 303 & 26 & $0.079(0.052$ to 0.114$)$ & $0.146(0.096$ to 0.20$)$ & 2.16 (1.65 to 2.83$)$ \\
\hline \multicolumn{9}{|c|}{ Birth year 1919 or earlier } \\
\hline Male MZ & 218 & 44 & 0.101 (0.073 to 0.129 & 30 & 7 & $0.189(0.080$ to 0.352$)$ & $0.318(0.14$ to 0.50$)$ & 3.15 (1.88 to 5.28$)$ \\
\hline Male DZ & 389 & 53 & $0.068(0.052$ to 0.088$)$ & 45 & 4 & $0.082(0.023$ to 0.196$)$ & 0.151 (0.02 to 0.28$)$ & $2.22(1.11$ to 4.41$)$ \\
\hline Female MZ & 323 & 90 & $0.139(0.113$ to 0.166$)$ & 74 & 8 & $0.098(0.043$ to 0.183$)$ & $0.178(0.07$ to 0.28$)$ & 1.28 (0.78 to 2.07$)$ \\
\hline Female DZ & 655 & 194 & $0.148(0.129$ to 0.167$)$ & 158 & 18 & $0.102(0.058$ to 0.147$)$ & $0.186(0.11$ to 0.26$)$ & 1.25 (0.91 to 1.73$)$ \\
\hline \multicolumn{9}{|c|}{ Birth year 1920-45 } \\
\hline Male MZ & 869 & 45 & $0.026(0.019$ to 0.035$)$ & 43 & 1 & $0.023(0.001$ to 0.120$)$ & $0.044(-0.04$ to 0.13$)$ & $1.72(0.43$ to 6.86$)$ \\
\hline Male DZ & 2234 & 128 & $0.029(0.024$ to 0.034$)$ & 128 & 0 & $0.000(0.000$ to 0.028$)$ & 0.000 & 0.00 \\
\hline Female MZ & 898 & 71 & $0.040(0.031$ to 0.050$)$ & 59 & 6 & $0.092(0.035$ to 0.190$)$ & 0.169 (0.051 to 0.29$)$ & 4.28 (2.43 to 7.51$)$ \\
\hline Female DZ & 1963 & 161 & $0.041(0.035$ to 0.048$)$ & 145 & 8 & $0.052(0.023$ to 0.100$)$ & $0.099(0.036$ to 0.16$)$ & 2.42 (1.49 to 3.95$)$ \\
\hline
\end{tabular}


meaningful site specific analyses; a table of the full results can be found on the BMJ's website.

\section{Discussion}

Our study indicates that in elderly women genetic factors are only weakly related to the likelihood of hospital admission for an osteoporotic fracture. As twin estimates of heritability are likely to represent the upper boundary of the genetic effects ${ }^{26-28}$ the modest genetic effect seen in men should not be emphasised too much either. On the other hand because just a small number of male pairs were concordant for fractures (eight monozygotic pairs and four dizygotic pairs), only the coming years will show the true fracture development in our male twin cohort. In this respect our results for women are more convincing, but again, more incident cases will be needed to increase the statistical power of the study and thus for more definitive conclusions. ${ }^{29}$ This will be especially important for different fracture types as family history studies seem to suggest that a positive family history for a specific fracture (wrist, hip) increases risk only for that specific fracture. $^{3031}$

Although the data on fractures were collected only from hospital admissions, which represent in some fracture types (such as wrist and vertebral fractures) only a proportion of the fractures in the population, it was unlikely that the people admitted to hospital were selected according to zygosity. So we think that the conclusions of this study are unbiased and valid.

The reason for our finding in women (that is, we could not show that the presumptive genetic effect on bone mass and density had an important role in explaining variation between individuals in risk for osteoporotic fracture) cannot be understood by looking at the results of previous studies that evaluated the risk factors for osteoporosis per se. A review of the recent studies of risk factors for osteoporotic fractures $^{30}{ }^{32-37}$ indicates that the determinants of an osteoporotic fracture are largely independent of bone mass and density. These studies have suggested that in the pathogenesis of osteoporotic fractures, the falling, the direction and mechanism of falling, the protective neuromuscular responses, the impact energy created by the fall, and the capacity of the soft tissues around the impact site to absorb energy rather than bone quality and quantity are the main determinants of the fracture, and it is easy to understand that these determinants, especially falling, are largely controlled by unshared environmental factors. ${ }^{30}{ }^{32-37}$

Our results could help to enlarge our view on prevention of osteoporosis. As prevention of fractures in elderly people is the ultimate goal in prevention and treatment of osteoporosis, the population level strategies for fracture prevention could, in addition to the traditional means of increasing peak bone mass and preventing age related bone loss, include serious efforts for diminution of the number and severity of falls in older adults and protection of the critical anatomical sites of the body when a fall occurs. The first interventions in prevention of falls in elderly people and protection of their proximal hip by external protectors have been promising, ${ }^{38}{ }^{39}$ giving hope that the increasing number of age related fractures could be controlled.
- Genetic factors have a substantial role in explaining age specific variation in bone mass and density, but no previous study has directly evaluated whether they have a role in the variation of risk of osteoporotic fracture, the true end point of the entire osteoporosis problem

- Genetic factors are not strongly related to likelihood of osteoporotic fracture, particularly in elderly women

- For this reason, the traditional prevention strategy of osteoporotic fractures-increasing peak bone mass and preventing age related bone loss-could include new additional elements, such as prevention of falls in elderly people and protection of the critical anatomical sites of the body when a fall occurs

We thank the Finnish Ministry of Health for its cooperation and permission to use the hospital discharge data in the study.

Contributors: PK carried out the study, was involved in the design and analysis of the data, and wrote the basic manuscript. $\mathrm{MP}$ and JP were involved in the study design, data analysis, and writing of the paper. JK was involved in the design, data management, analysis of the study, writing of the paper, and organisation of funding. MK contributed to the study design and analysis, finalisation of the manuscript, and organisation of funding. PK is the guarantor.

Funding: Medical Research Fund of Tampere University Hospital, Tampere, Finland, and the Academy of Finland (grants no 38332 and 42044).

Competing interests: None declared.

1 Cummings SR, Black DM, Nevitt MC, Browner W, Cauley J, Ensrud K, et al. Bone density at various sites for prediction of hip fractures. Lancet 1993;341:72-5.

2 Kannus P, Parkkari J, Niemi S. Age-adjusted incidence of hip fractures. Lancet 1995;346:50-1.

3 Kannus P, Parkkari J, Niemi S, Palvanen M. Epidemiology of osteoporotic ankle fractures in elderly persons in Finland. Ann Intern Med 1996;125:975-8.

4 Melton LJ III. Hip fractures: a worldwide problem today and tomorrow. Bone 1993;14:S1-8.

5 Cooper C, Atkinson EJ, Jacobsen SJ, O'Fallon WM, Melton LJ III. Population-based study of survival after osteoporotic fractures. Am J Epidemiol 1993;137:1001-5.

6 Dempster DW, Lindsay R. Pathogenesis of osteoporosis. Lancet 1993:341:797-805.

7 Hui SL, Slemenda CW, Johnston CC Jr. Baseline measurement of bone mass predicts fracture in white women. Ann Intern Med 1989;111:355-61.

8 Smith DM, Nance WE, Kang KW, Christian JC, Johnston CC Jr. Genetic factors in determining bone mass. J Clin Invest 1973;52:2800-8.

9 Pocock NA, Eisman JA, Hopper JL, Yeates MG, Sambrook PN, Eberl S. Genetic determinants of bone mass in adults: a twin study. J Clin Invest 1987;80:706-10.

10 Evans RA, Marel GM, Lancaster EK, Kos S, Evans M, Wong SYP. Bone mass is low in relatives of osteoporotic patients. Ann Intern Med 1988;109:870-3.

11 Seeman E, Hopper JL, Bach LA, Cooper ME, Parkinson E, McKay J, et al. Reduced bone mass in daughters of women with osteoporosis. N Engl J Med 1989;320:554-8.

12 Krall EA, Dawson-Hughes B. Heritable and life-style determinants of bone mineral density. J Bone Miner Res 1993;8:1-9.

13 Flicker L, Hopper JL, Rodgers L, Kaymakci B, Green RM, Wark JD. Bone density determinant in elderly women: a twin study. J Bone Miner Res 1995; 10:1607-13.

14 Cederlöf R, Friberg L, Jonsson E, Kaij L. Studies on similarity diagnosis in twins with the aid of mailed questionnaires. Acta Genet Stat Med 1961;11:338-62.

15 Jablon S, Neel JV, Gershowitz H, Atkinson GF. The NAS-NRC twin panel: methods of construction of the panel, zygosity diagnosis and proposed use. Am J Hum Genet 1967;19:133-61.

16 Magnus P, Berg K, Nance WE. Predicting zygosity in Norwegian twin pairs born in 1915-1960. Clin Genet 1983;24:103-12.

17 Sarna S, Kaprio J, Sistonen P, Koskenvuo M. Diagnosis of twin zygosity by mailed questionnaire. Hum Hered 1978;28:241-54.

18 Rose RJ, Koskenvuo M, Kaprio J, Sarna S, Langinvainio H. Shared genes, shared experiences, and similarity of personality: data from 14,288 adult Finnish cotwins. J Personal Soc Psychol 1988;54:161-71. 
19 Jones G, Ngyen T, Sambrook PN, Kelly PJ, Gilbert C, Eisman JA. Symptomatic fracture incidence in elderly men and women: the Dubbo osteoporosis epidemiologic study (DOES). Osteoporosis Int 1994;4: $277-82$.

20 Lauritzen JB, Schwarz P, Lund B, Mcnair P, Transpøl I. Changing incidence and residual lifetime risk of common osteoporosis-related fractures. Osteoporosis Int 1993;3:127-32.

21 Salmela R, Koistinen V. Coverage and accuracy of the hospital discharge register (in Finnish). Hospital 1987;49:480-2.

22 Keskimäki I, Aro S. Accuracy of data on diagnosis, procedures and accidents in the Finnish hospital discharge register. Int J Health Sci 1991;2: $15-21$.

23 Lüthje P, Nurmi I, Kataja M, Heliövaara M, Santavirta S. Incidence of pelvic fractures in Finland in 1988. Acta Orthop Scand 1995;66:245-8.

24 Falconer DS. Introduction to quantitative genetics. Harlow, Essex: Longman, 1981.

25 Emery EM. Methodology in medical genetics: an introduction to statistical meth ods. Edinburgh: Churchill Livingstone, 1976.

26 Heath AC, Neale MC, Hewitt JK, Eaves LJ, Fulker DW. Testing structural equation models for twin data using LISREL. Behav Genet 1989;19:9-35.

27 Slemenda CW, Christian JC, Williams CJ, Norton JA, Johnston CC J Genetic determinant of bone mass in adult women: a reevaluation of the twin model and the potential importance of gene interaction on heritability estimates.J Bone Miner Res 1991;6:561-7.

28 Spector TD, Cicuttini F, Baker J, Loughlin J, Hart D. Genetic influences on osteoarthritis in women: a twin study. BMJ 1996;312:940-4.

29 Neale MC, Eaves LJ, Kendler KS. The power of the classical twin study to resolve variation in threshold traits. Behav Genet 1994:24:939-58.
30 Cummings SR, Nevitt MC, Browner WS, et al. Risk factors for hip fracture in white women. $N$ Engl J Med 1995;332:767-73.

31 Fox KM, Cummings SR, Powell-Threets K, Stone K for the Study of Osteoporotic Fractures Research Group. Family history and risk of osteoporotic fracture. Osteoporos Int 1998;8:557-62.

32 Nevitt MC, Cummings SR. Type of fall and risk of hip and wrist fractures: the study of osteoporotic fractures. J Am Geriatr Soc 1993;41:1226-34.

33 Greenspan SL, Myers ER, Maitland LA, Resnick NM, Hayes WC. Fall severity and bone mineral density at risk factors for hip fracture in ambulatory elderly. JAMA 1994;271:128-33.

34 Dargent-Molina P, Favier F, Grandjean H, et al. Fall-related factors and risk of hip fracture: the EPIDOS prospective study. Lance $1996: 348: 145-9$.

35 Marshall D, Johnell O, Wedel H. Meta-analysis of how well measures of bone mineral density predict occurrence of osteoporotic fractures. $B M$ J 1996;312:1254-9.

36 Nguyen TV, Eisman JA, Kelly PJ, Sambrook PN. Risk factors for osteoporotic fractures in elderly men. Am J Epidemiol 1996;144:255-63.

37 De Laet CEDH, van Hout BA, Burger H, Hofman A, Pols HA. Bone density and risk of hip fracture in men and women: cross sectional analysis. BMJ 1997;315:221-5

38 Tinetti ME, Baker DI, McAvay G, Claus EB, Garrett P, Gottschalk M, et al. A multifactorial intervention to reduce the risk of falling among elderly people living in the community. N Engl J Med 1994;331:821-7.

39 Lauritzen JB, Petersen MM, Lund B. Effect of external hip protectors on hip fractures. Lancet 1993;341:11-3.

(Accepted 24 August 1999)

\title{
High penetrance, overweight, and glucocorticoid receptor variant: case-control study
}

\author{
Ruby C Y Lin, William Y S Wang, Brian J Morris
}

A possible link between the glucocorticoid receptor gene (GRL, 5q31-q32) and overweight has been suggested in a study of 42 families with morbid obesity. ${ }^{1}$ Data from another small study-of pairs of siblings-although not significant, showed a trend towards similar body mass index (weight $(\mathrm{kg}$ )/ (height $\left.(m)^{2}\right)$; difference $=2.4$ ) for 20 pairs sharing similar alleles compared with 19 pairs having discordant alleles (difference $=3.5$ ). ${ }^{2}$ An Asn363Ser variant, caused by a single nucleotide difference (A1218G) in exon 2 of GRL has since shown an association with increased sensitivity to glucocorticoids. ${ }^{3}$ Because of the predisposition to a rise in body mass index that this increased sensitivity should cause, we tested this variant for association with overweight in two groups of non-diabetic white subjects of British descent.

\section{Methods and results}

All participants lived in or near Sydney and had responded to requests to take part in a study that involved DNA testing. Because of the interaction between obesity and hypertension we selected subjects on the basis of a positive or negative family history of hypertension and tested them separately. Group 1 was recruited from donors at the Sydney Blood Bank and comprised 195 subjects who were normotensive offspring of two normotensive parents. Group 2 comprised 124 subjects recruited by public advertising for people with essential hypertension whose parents also had hypertension. Mean body mass index was 26 (SD 4) in group 1 and 26 (SD 5) in group 2; mean age was 48 (SD 10) years and 52 (SD 12) years respectively; percentage of male participants was $57 \%$ and $49 \%$ respectively; and blood pressure was 120 (SD 11)/73 (SD 8) $\mathrm{mm} \mathrm{Hg}$ and 173 (SD 24)/110 (SD 17) mm Hg respectively.

Each group was divided into two subgroups: lean (body mass index $\leq 25)$ and overweight (>25). Genotyping was performed on leucocyte DNA using polymerase chain reaction primers described previously ${ }^{4}$ and Tsp509I digestion of polymerase chain reaction products, which gave a band of 134 base pairs for the Asn363 variant and 153 base pairs for the Ser363 variant, together with a band of 95 base pairs for both.

The frequency of the Ser363 variant (number of Ser363 alleles divided by total number of alleles) in each group was similar ( $7.4 \%$ (95\% confidence interval $4.8 \%$ to $10.0 \%)$ in group $1 v 6.0 \%(3.1 \%$ to $9.0 \%)$ in group 2), with $12.3 \%$ ( $7.7 \%$ to $16.9 \%$ ) in group 1 being carriers (that is, they had one or two alleles) and 10.5\% $(5.1 \%$ to $15.9 \%)$ in group 2 . In participants with body mass index $\leq 25$ the Ser363 allele was rare $(1.8 \%$ in group 1 and $0 \%$ in group 2). All Ser/Ser homozygotes were overweight, as were all Asn/Ser heterozygotes in group 2 and $80 \%$ of Asn/Ser heterozygotes in group 1 (table). Association with overweight was highly significant (table), with overall penetrance in participants with the Ser363 variant being 83\% in group 1 and $100 \%$ in group 2. Consistent with this, the higher the body mass index, the more likely the subject was to have the Ser363 variant (table).

\section{Comment}

We found that the Ser363 variant of the glucocorticoid receptor confers a virtually absolute likelihood of being overweight-unlike most markers
Gene Laboratory, Department of Physiology and Institute for Biomedical Research, Building F13, University of Sydney, Sydney,

NSW 2006

Australia

Ruby C Y Lin

PhD student

William Y S Wang master of medicine student

Brian J Morris professor of physiology

Correspondence to: B J Morris brianm@physiol. usyd.edu.au

BMJ 1999;319:1337-8 